\title{
Research Paper: Emergency Accommodation and Post-earthquake Logistics Management Using Damage Analysis Results
}

\author{
Saadi Ghaderi ${ }^{1}$, Khadijeh Norouzi Khatiri ${ }^{2 *}$ (D), Sajad Ganjehi ${ }^{3}$ (D) \\ 1. Isfahan Water Regional Company, Isfahan, Iran. \\ 2. Department of Engineering, Faculty of Environment, University of Tehran, Iran. \\ 3. Disaster Management, Faculty of Engineering, University of Tehran, Tehran, Iran.
}

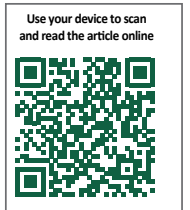

Citation: Ghaderi S, Norouzi Khatiri Kh, Ganjehi S. Emergency Accommodation and Post-earthquake Logistics Management Using Damage Analysis Results. Health in Emergencies and Disasters Quarterly. 2021; 6(2):99-114. http://dx.doi.org/10.32598/ hdq.6.2.350.1

http://dx.doi.org/10.32598/hdq.6.2.350.1

\section{Keywords:}

Risk analysis, Earthquake, Temporary settlement, Analytic hierarchy process

\section{ABSTRACT}

Background: Iran is an earthquake-prone country, and a considerable rural population lives in earthquake-prone areas. With many worn-out areas, incompetent houses, and relatively underdeveloped rural areas, it is necessary to pay special attention to risk reduction and subsequent measures in these areas.

Materials and Methods: Among the current methods, HAZUS is one of the most common methods in estimating potential losses in an earthquake. We used it to calculate the buildings' estimated losses in the earthquake based on the instructions. Because one of the main issues in disaster management is to choose locations for emergency or temporary settlement of population affected by the distracter, this research tries to carry this out based on the derived results from the damage using fuzzy Analytic Hierarchy Process (AHP). After reviewing the previous studies and the experts' opinions, the major and minor criteria affecting the selection of temporary settlement locations were identified.

Results: Results suggested that using the damage rate of the studied buildings in the studied area and after choosing six priorities in the pilot village of Vaneshan, priority number 1 was chosen as the best option for temporary settlement in this village. Ultimately, the required items for the evacuees were determined by using the standards of supplying the essentials for the evacuees.

Conclusion: Regarding the study area, the results of the damage analysis of the area show that the rate of damage with extensive and complete levels in the villages is very high, which leads to a large number of homeless people with the urgent need to provide adequate shelter. This endower requires a lot of money, and the relevant managers should already be thinking about finding financial resources for it. This issue is not only related to the study area and applies to the whole of Iran. 


\section{Introduction}

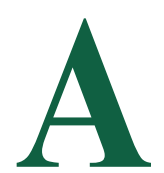

statistics review on the damages for natural disasters during the past two decades in different parts of the world show an increase in these damages and their economic consequences so that the average annual human losses from the natural disasters from $\$ 20$ billion in 1990 have reached $\$ 70$ billion in 2004 [1]. This amount went even higher and reached $\$ 250$ billion in 2005 for disasters such as Hurricane Katrina and Hurricane Rita in the US and several floods in Europe and Asia [2].

Today, the hazards of natural disasters are felt even more due to the concentration of population and material and human capitals, increase in the vulnerability of these capitals, the weaknesses in prediction and high levels of damages, and a high risk of natural disasters in most of the world [3]. Hence, it seems necessary to adopt preventive measures to decrease the damages and losses due to these natural disasters, considering the current facilities. Also, the influence of different factors on the damages should be studied, and different approaches should be analyzed, and the best management approaches are selected by considering the priorities [4].

In their study entitled "Seismic Retrofitting of NonEngineered Masonry in Rural Nepal," Macabuag et al. [5] proposed using the polypropylene meshing method to prevent or prolong the collapse time in brickwork buildings under strong earthquakes. This method is effective in retrofitting non-engineered masonry in rural areas, considering the ease of implementation, economic efficiency, and application in even strong earthquakes.

Using ArcGIS and Analytic Hierarchy Process (AHP) and also by applying major criteria such as the distribution of intra-city train tracks, urban streets, population density and buildings, and related sub-criteria, Qiang Wu et al. [6] proposed the vulnerability map of Yuci, in Shanxi Region in China.

Using Geographic Information System (GIS) and AHP and other criteria such as land use, slope, and land quality and height, Tudes et al. [7] provided the zoning map of the relative risk of earthquake for Adana County. It is one of Turkey's most earthquake-prone regions and used it to locate urban usages using the map.

In a study using different environmental and economic criteria and using GIS and AHP, Donevska et al. [8] located the low-risk areas for the natural disasters in the Polog region of Macedonia. Liue et al. [9] studied the
2010 earthquake in Yushu District (7.1 magnitudes) in China with 2698 casualties and focused on the experiences of reconstruction and restoration of the region along with expressing the factors affecting the intensity of the damage in the area and the role of governmental organizations and institutions in relieving the victims, including settlement. This study identified the region's particular condition and lack of infrastructural facilities for reliving as the factors affecting the severity of casualties. In a study entitled "Seismic Risk Assessment for Rural Areas," Kaptan [10] carried out the quick and straightforward seismic risk assessment, using geological and social data and by defining risk and vulnerability.

This research proposes an efficient method by a flexible and robust system, using the concept of damage analysis combination, fuzzy model, and AHP. These methods are used to measure the damage and earthquake risk, to determine the best location for temporary settlement using GIS, and ultimately, to figure out the essential items in the studied village. The study's main objective is the analysis of the damage risk in rural buildings against possible earthquakes and estimation of possible damages by considering the possibility of this risk. Based on what was discussed, one of the main factors that the responsible organizations in crisis management have always considered is to choose a location for emergency or temporary settlement of the populations affected by the disasters. In Iran and most of the other parts of the world, location selection for the citizens' emergency settlement is carried out based on the experiences after the disaster, without considering the required standards by the aiding organizations. However, the lack of correct selection might lead to problems far worse than the first disaster. Hence, the need for planning, management, and proposing proper strategies for emergency or temporary settlement of the affected population before the earthquake is significantly felt. Also, to carry out crisis management in the earthquake-affected areas, an integrated logistics system should be designed and implemented. The crisis logistic system should enforce the policies and instructions of the headquarters and should respond to the requests and needs on time. All of these measures are possible only if a comprehensive understanding of the society and potential hazards and accidents in the city has been reached and society risk maps have been developed.

\section{Materials and Methods}

Golpayegan County is among the counties located in the western part of Isfahan Province, Iran. It is located $186 \mathrm{~km}$ away from Isfahan County. The geographical coordinates of the county are Longitude; $49^{\circ} 57^{\prime}-50^{\circ}$ 


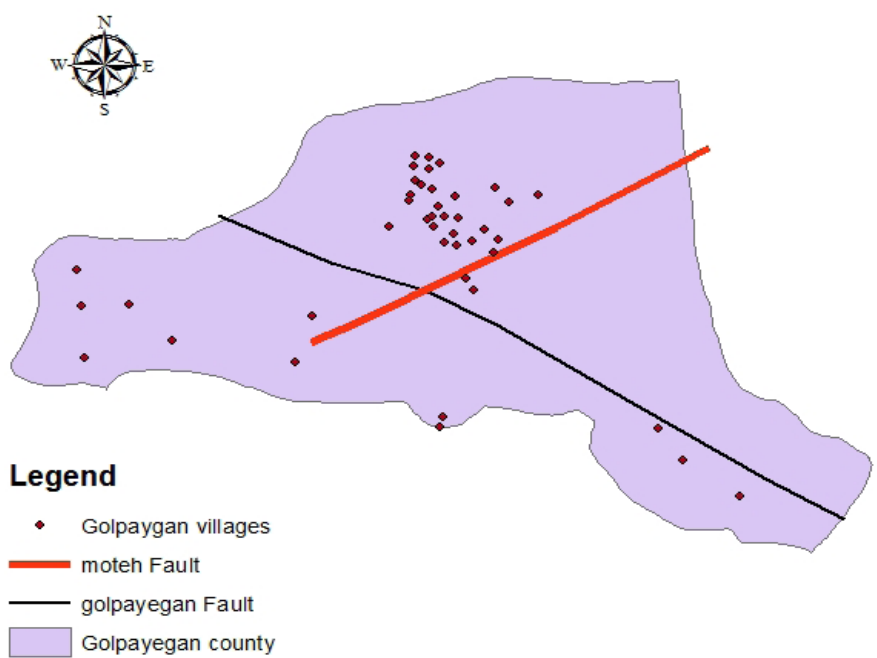

Figure 1. The location of studied region (Golpayegan County)

Health in
Emergencies and |Disasters [O]uarterly $45^{\prime} \mathrm{E}$ and Latitude; $33^{\circ} 14^{\prime}-33^{\circ} 28^{\prime} \mathrm{N}$. According to a 2016 survey, of the total of 90086 population, 74852 live in the cities, and 15234 in the villages of the county. Figure 1 presents the location of Golpayegan County and its villages.

As shown in Figure 2, this study's research method included the earthquake risk analysis module, earthquake damage analysis module, the ultimate temporary settlement module, and ultimately, the number of logistic items required by the village. Each of these is explained in the following.

As shown in the flowchart, the study instruments include the statistical methods for determining the possible earthquake damage in different damage levels, determining the possibility of earthquake occurrence, using ArcGIS, and ultimately determining the earthquake risk percentages in different levels of each village. The study software is ArcGIS, and by linking the tables of conducted analyses of the damages due to the disasters on the building blocks and also the possibility of disaster occurrence, the data were inserted in ArcGIS layers. Using the combination of the layers and calculating the risk, the risk percentage maps in different damage levels were prepared. Also, the following procedures were carried out for the management of decision-making stages. In this study, the fuzzy AHP method and Extent Analysis (EA) of Young Chang were used. Besides, in the paired comparison table of the fuzzy AHP method, three numbers were assigned for each comparison. All the data related to comparisons are in the form of fuzzy triangular numbers (maximum, most probable, minimum). The standard fuzzy AHP tables were distributed among the experts. These experts were chosen based on their knowledge of decision-making factors and their work experience (more than 10 years' experience). After combining the paired comparison tables, using the geometric mean, and calculating the final tables of paired comparisons, the fuzzy data were inserted in Excel and MATLAB, and the ultimate weight related to each table was calculated. Finally, using the pilot village maps, the emergency settlement location was determined. Also, the logistic items required in this village were determined based on the current instructions.

\section{Attenuation relationship}

To analyze the risk, we used the attenuation relationship of Zare' [11]. Based on research on the Iranian Strong-Motion Data collected from all over Iran and selecting 498 three-component maps and modifying them, Zare' et al. provided attenuation relationships for Iran. The attenuation model of calculating the maximum acceleration and ground speed [11] is as the following (Equation 1):

\section{1. $\log A=a \cdot M+b \cdot X-\log X+C S_{i}+\sigma \cdot p$}

, where $\mathrm{A}$ is the studied parameter (acceleration or maximum speed of the ground), $\mathrm{M}$ is the magnitude of the earthquake, $\mathrm{X}$ is the focal distance $(\mathrm{km}), \mathrm{C}$ is the site factor $(\mathrm{S})$, and $\sigma$ is the standard deviation. The Standard Deviation is added to the mean value $(\mathrm{P}=0)$ by assuming $\mathrm{P}=1$. $\mathrm{C} 1$ is related to a stone site, $\mathrm{C}_{2}$ is related to the hard alluvium site, $\mathrm{C}_{3}$ is related to the soft alluvium (sand) site, and $\mathrm{C}_{4}$ is related to the soft (clay) site. The coefficient used in Zare' et at. [11] attenuation relationship is presented in Table 1. 


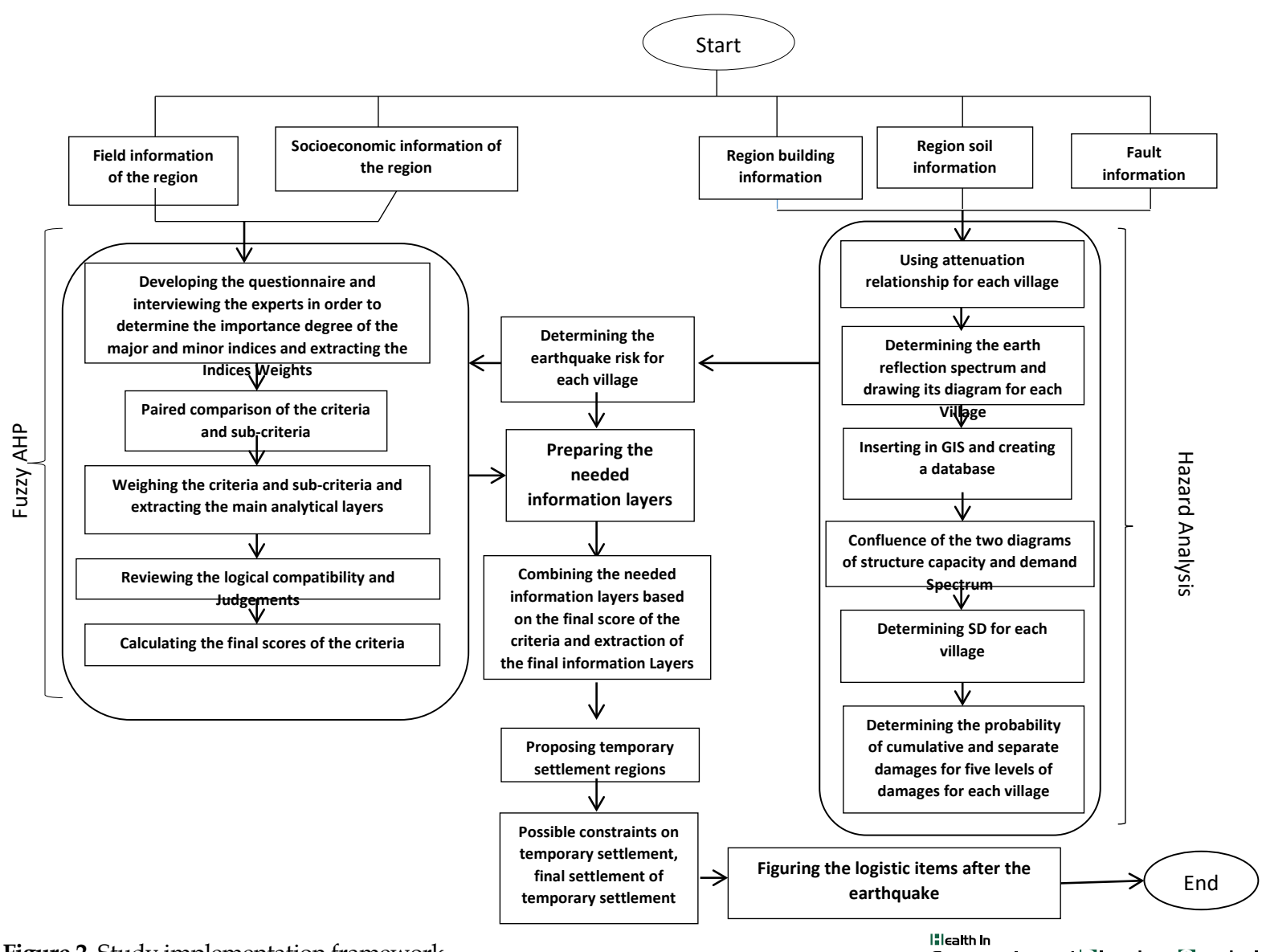

Figure 2. Study implementation framework

Emergencies and |D]isasters [Oluarterly

Considering the carried-out studies, the site of the studied region is in the hard alluvium categorization. Hence, $\mathrm{S}_{2}=1$, and $\mathrm{S}_{1}, \mathrm{~S}_{3}$, and $\mathrm{S}_{4}$ are equal to zero.

\section{Building capacity curve and demand spectrum}

Considering the HAZUS [12] instruction, the SAs (short-period spectral acceleration of soil type i) and SALi (spectral acceleration of 1 second period of soil type i) was determined based on the region shear wave velocity and soil type (Equation 2). It was modified by Formulas 4.

$$
\text { 2. } S_{A S i}=S_{A S} F_{A i} \cdot S_{A L i}=S_{A L} F_{V i} \cdot T_{A V i}=\left(\frac{S_{A S i}}{S_{A S}}\right)\left(\frac{F_{V i}}{F_{A i}}\right)
$$

Also, the standard response spectrum, which includes the following, was calculated.

- Constant acceleration (in the time interval lesser than TAV, the constant numerical acceleration is equal to SAS).

Table 1. Attenuation relationship components (Zare', 1999)

\begin{tabular}{|c|c|c|c|c|c|c|c|}
\hline Region & A & B & $\mathrm{C}_{1}$ & $\mathrm{C}_{2}$ & $\mathrm{C}_{3}$ & $\mathrm{C}_{4}$ & $\boldsymbol{\sigma}$ \\
\hline Central Iran - Alborz (vertical component) & 0.322 & -0.0003 & -0.828 & -0.754 & -0.971 & -0.788 & 0.352 \\
\hline Central Iran - Alborz (horizontal component) & 0.322 & -0.0004 & -0.688 & -0.458 & -0.72 & -0.585 & 0.394 \\
\hline Zagros (vertical component) & 0.406 & -0.0038 & -1.262 & -1.333 & -1.23 & -1.777 & 0.356 \\
\hline Zagros (horizontal component) & 0.339 & -0.0019 & -1.047 & -1.065 & -1.02 & -0.975 & 0.329 \\
\hline Iran (vertical component) & 0.362 & -0.0002 & -1.124 & -1.15 & -1.139 & -1.064 & 0.336 \\
\hline Iran (horizontal component) & 0.36 & -0.0003 & -0.916 & -0.852 & -0.9 & -0.859 & 0.333 \\
\hline
\end{tabular}




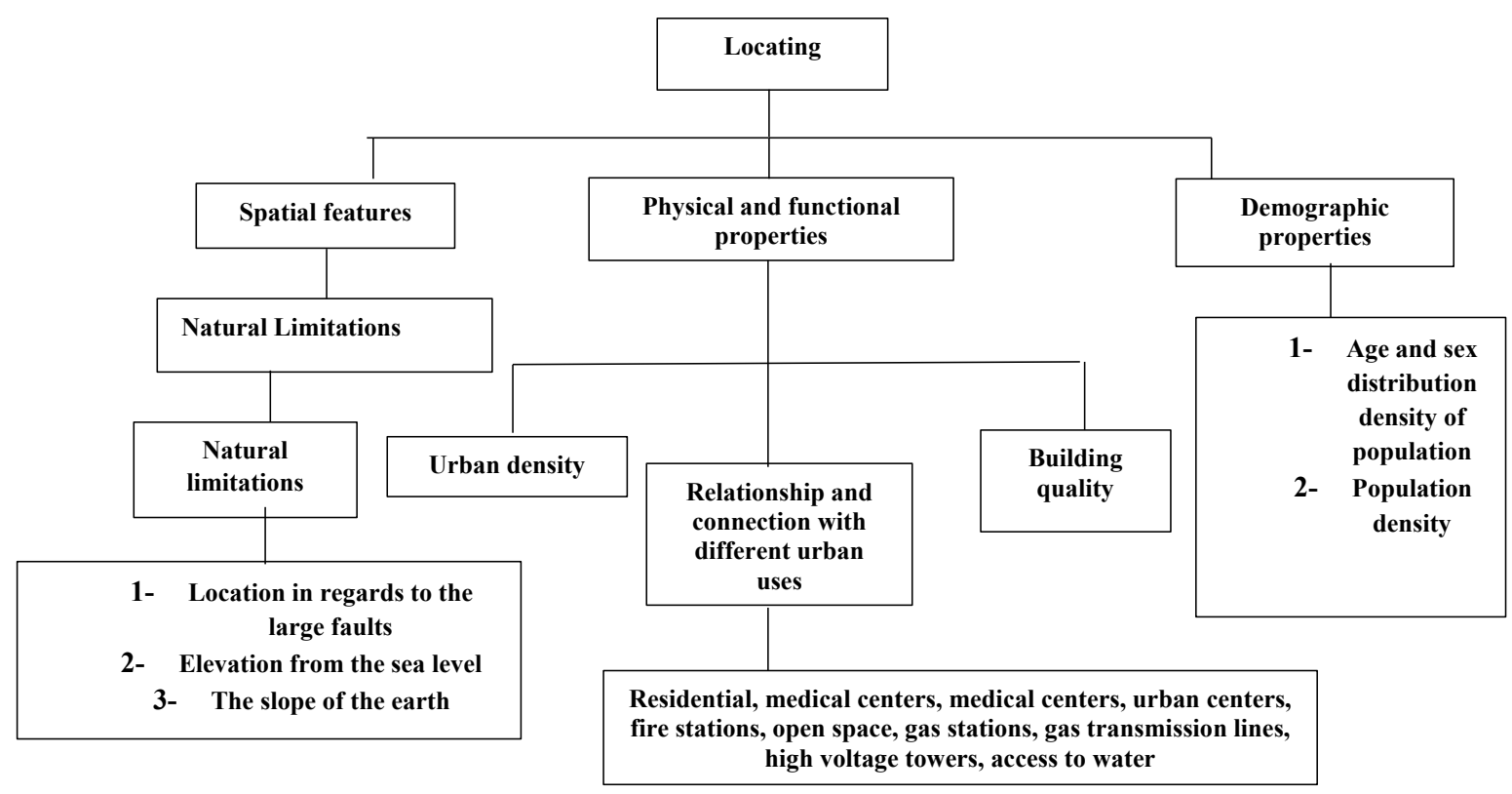

Figure 3. Emergency settlement location criteria

- Constant speed (in the time interval of $\mathrm{T}_{\mathrm{AV}}<\mathrm{T}<\mathrm{T}_{\mathrm{VD}}$, the acceleration corresponds with $1 / \mathrm{T}$ ).

- Constant displacement (in the time interval of $\mathrm{T}>\mathrm{T}_{\mathrm{VD}}$, the acceleration corresponds with $1 / \mathrm{T}^{2}$ ).

\section{Earthquake damage analysis module}

Considering the abovementioned details, the seismic demand spectrum and building capacity curve were calculated and drawn. For example, Figure 3 presents the intersection of the two diagrams of seismic demand spectrum and building capacity on masonry structure. Considering the SDs calculated from the abovementioned diagrams and the median and $\beta$ of each structure, the cumulative probability was calculated for five levels of damage in the buildings considering Equation 3. Subsequently, considering Equations 4, the discreet probability for different levels of damage was calculated.

$$
\text { 3. } P\left(d_{s} \mid S_{d}\right)=\varphi\left(\frac{1}{\beta d s} \ln \left(\frac{S_{d}}{S_{d, d s}}\right)\right)
$$

In Equation 3, Sd.ds is the median of spectrum displacement in damage state of $\mathrm{ds}, \beta \mathrm{ds}$ is the standard deviation of the natural logarithm of spectral displacement for the damage stage of $\mathrm{ds}$, and $\phi$ is the normalized cumulative distribution function.

$$
\begin{aligned}
& \text { 4. } P_{\text {COMB }}[D S=C]=P_{\text {COMB }}[D S \geq C] \\
& P_{\text {COMB }}[D S=E]=P_{C O M B}[D S \geq E]-P_{\text {COMB }}[D S \geq C]
\end{aligned}
$$

$$
\begin{aligned}
& P_{\text {COMB }}[D S=M]=P_{\text {COMB }}[D S \geq M]-P_{\text {COMB }}[D S \geq E] \\
& P_{\text {COMB }}[D S=S]=P_{C O M B}[D S \geq S]-P_{C O M B}[D S \geq M] \\
& P_{\text {COMB }}[D S=N o n e]=1-P_{\text {COMB }}[D S \geq S]
\end{aligned}
$$

Locating the emergency settlement

Considering the effective factors in the emergence of problems in temporary settlement operation and identifying the damaging factors of different urban uses, the locating criteria can be seen in Figure 3.

In this study, using AHP (Expert Choice software), the criteria were weighed, and integration and fuzzy logic (ArcGIS) were used.

Locating process is carried out based on modeling the current situation and the predicated condition. It is carried out by the conceptual modeling of MacCoy and Johnston. Based on this method, locating these centers is carried out using a particular analyzer through the convenient location's maps (convenient location's map is a map that shows the most and least convenient places for the location of a certain activity based on a special subject, e.g. fault). The analyzed subjects in these studies were conducted based on the data layers proposed in the positioning model. The element analysis process to create a map is carried out in two steps so that in the first stage, the convenient location maps are prepared for some elements, and after combining them with other elements, the initial map of the convenient locations is 


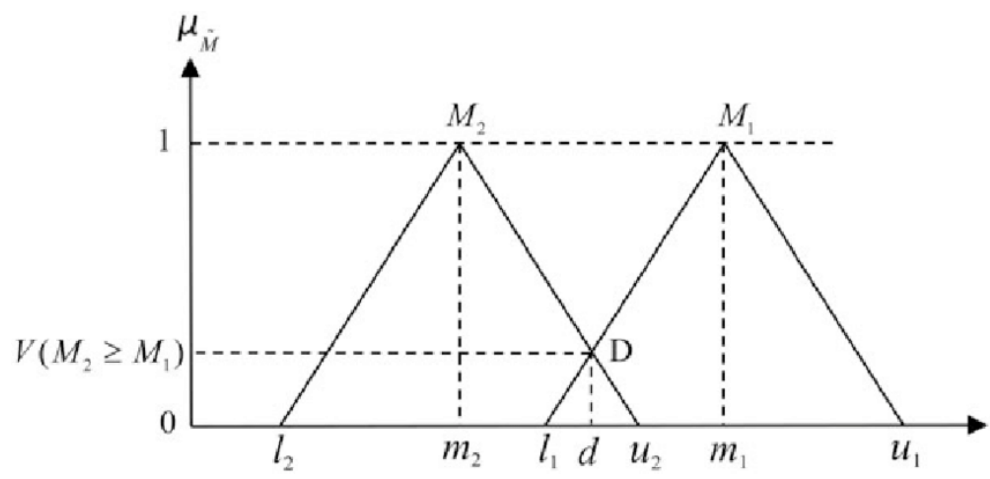

Figure 4. M1 and M2 triangular numbers

prepared for creating the settlement centers. In the second stage, by inserting other maps, such as the limits, the convenient locations for the settlement centers are determined in the studied scope.

\section{Chang extent analysis method}

In 1996, a method entitled the "Extent Analysis" method was proposed by a Chinese researcher named Chang. The numbers used in this method are fuzzy triangular numbers. The concepts and definitions of fuzzy AHP are expressed based on the EA method [13]. There are two fuzzy triangular numbers of $\mathrm{M} 1=\left(\mathrm{l}_{1}, \mathrm{~m}_{1}, \mathrm{u}_{1}\right)$ and $\mathrm{M}_{2}=\left(\mathrm{l}_{2}\right.$, $\mathrm{m}_{2}, \mathrm{u}_{2}$ ) in Figure 4. Hence, Equations 5-7 are held:

$$
\begin{aligned}
& \text { 5. } M_{1}+M_{2}=\left(l_{1}+l_{2}, m_{1}+m_{2}, u_{1}+u_{2}\right) \\
& \text { 6. } M 1 \times M 2=\left(l_{1} \times l_{2}, m_{1} \times m_{2}, u_{1} \times u_{2}\right) \\
& \text { 7. } M_{1}^{-1}=\left(\frac{1}{u_{1}} \cdot \frac{1}{m_{1}} \frac{1}{l_{1}}\right) \cdot M_{2}^{-1}=\left(\frac{1}{u_{2}} \cdot \frac{1}{m_{2}} \cdot \frac{1}{l_{2}}\right)
\end{aligned}
$$

It should be mentioned that the product of the multiplication of two fuzzy triangular numbers or the inverse of a fuzzy triangular number is not another triangular number. These equations only estimate the real product of the multiplication of two fuzzy triangular numbers or the inverse of a fuzzy triangular number. For each line of paired comparison matrix in the EA method, the $S_{k}$ value, which is a fuzzy triangular number, is calculated in the form of Equation 8:

$$
\text { 8. } S_{K}=\sum_{J=I}^{n} M_{K J} *\left[\sum_{I=}^{m} \sum \stackrel{n}{M}=i j^{-1}\right.
$$

$\mathrm{K}$ is the number of the line, $\mathrm{i}$ and $\mathrm{j}$ are the choices and indices, respectively. In this method, after calculating $\mathrm{S}_{\mathrm{k}} \mathrm{s}$, their degree of greatness should be calculated relative to each other. Generally, if M1 and M2 are two fuzzy triangular numbers, the degree of greatness of M1 and M2 is defined by Equations 9 and 10.
9. $V\left(M_{1} \geq M_{2}\right)=1$ if $m_{1} \geq m_{2}$

10. $V\left(M_{1} \geq M_{2}\right)=\operatorname{hgt}\left(M_{1} \cap M_{2}\right)$ otherwise

Based on the similar properties of triangles, there is Equation 11:

$$
\text { 11. } h g t\left(M_{1} \cap M_{2}\right)=\frac{u_{1}-u_{2}}{\left(u_{1}-l_{2}\right)+\left(m_{2}-m_{1}\right)}
$$

The greatness of a fuzzy triangular number relative to $\mathrm{k}$ fuzzy triangular numbers could be calculated from Equation 12.

$$
\text { 12. } V\left(M_{1} \geq M_{2} \ldots . . M_{K}\right)=V\left(M_{1} \geq M_{2}\right) \ldots \ldots .\left(M_{1} \geq M_{K}\right)
$$

Also, to calculate the weight of the indices in the paired comparison matrix, the following is carried out (Equation 13):

$$
\text { 13. } W^{\prime \prime}\left(X_{i}\right)=\operatorname{Min}\left\{V\left(S_{i} \geq S_{K}\right)\right\} . \quad K=1.2 \ldots . n . \quad K \neq i
$$

Hence, the indices weight vector is as Equation 14:

$$
\text { 14. } W^{\prime}\left(X_{i}\right)=\left[W^{\prime}\left(C_{1}\right) \cdot W^{\wedge \prime}\left(C_{2}\right) \ldots . . W^{\prime}\left(C_{n}\right)\right]^{T}
$$

, where $\mathrm{W}^{\prime}$ is the non-normal coefficient vectors of fuzzy AHP.

Next, to determine the normalized or non-fuzzy weights, the Sa'ati normalization method is used based on Equation 15 by dividing any non-normal weight matrix element on the sum of the elements of the same matrix:

$$
\text { 15. } W_{i}=\frac{W_{i}^{\prime}}{\sum W_{i}^{\prime}}
$$

Wi is the normalized weights of the fuzzy AHP method. 


\section{Determining decision-makers weights}

As mentioned before, any of the paired comparisons is assigned a confidence level by the decision-makers. Then, all the confidence levels assigned by a decision-maker are combined to reach a general confidence level, and it is considered the weight of the decision-maker [14] (Equation 16).

\section{6. $\begin{cases}(1 & \text { High Confidence } \\ 0.5 & \text { Average confidence } \\ @, 0 & \text { Low Confidence }\end{cases}$}

If $\mathrm{W}^{\mathrm{k}}$ is the weight of the $\mathrm{k}^{\text {th }}$ decision-maker, it could be determined through the following steps. Initially, each linguistic confidence level is transformed into a numerical value. If $a_{x y k}$ is the numerical confidence level of the $\mathrm{k}^{\text {th }}$ decision-maker for the paired comparison of criterion $\mathrm{x}$ comparing to the criterion $\mathrm{y}$, then (Equation 17):

$$
\begin{aligned}
& |A-\lambda I|=0 \\
& \text { 17. }\left[\begin{array}{lll}
a_{11}-\lambda & a_{12} & a_{1 n} \\
a_{21} & a_{22}-\lambda & a_{2 n} \\
a_{n 1} & a_{n 2} & a_{n n}-\lambda
\end{array}\right]
\end{aligned}
$$

Subsequently, axyk is categorized on separate matrices of $\mathrm{A}_{\mathrm{ck}}=\mathrm{a}_{\mathrm{xyk}}$, similar to paired comparisons of AHP. In the next stage, the maximum specified value of the $A_{c k}$ matrix, which is represented as $\lambda_{\mathrm{ck}}$, is calculated. Subsequently, the $\mathrm{W}^{\mathrm{k}}$ value is derived from combining $\lambda_{\mathrm{ck}} \mathrm{s}$. Also, to calculate the specific value, the following equations could be used (Equations 18 and 19):

18. $b_{n} \lambda^{n}+b_{n-1} \lambda^{n-1}+\ldots+b_{0}=0 \rightarrow\left\{\begin{array}{l}\lambda_{1} \\ \lambda_{2} \\ \cdot \\ . \\ \lambda_{v}\end{array}\right.$

Because $\lambda_{\text {cks }}$ could change based on the $A_{\text {ck }}$ matrix size, Equation 16 is used for the $\lambda_{\text {cks }}$ to be in the interval of [0.1] (Equation 20).

20. $\lambda_{c k}{ }^{\prime}=\frac{\lambda_{c k}-\lambda_{c k}{ }^{\text {min }}}{\lambda_{c k}{ }^{\text {max }}-\lambda_{c k}{ }^{\text {min }}} ; \lambda_{c k}{ }^{\text {max }}=$ size of $A_{c k} \cdot \lambda_{c k}{ }^{\text {min }}=1$

$\lambda_{\mathrm{ck}}{ }^{\prime} \mathrm{i}$ is normalized through Equation 21:

21. $\lambda_{c k}{ }^{\prime \prime}=\frac{\lambda_{c k}{ }^{\prime}}{\sum_{j=1}^{r} \lambda_{c k}{ }^{\prime}}$

Hence, by combining $\lambda_{\text {ck }}$, all $\mathrm{W}^{\mathrm{k}}$ is calculated.

After this stage, using $\mathrm{a}_{\mathrm{mk}}$ (W') derived from the previous stages and the Ws derived from the previous stage for each paired matrix is presented by the decision-makers. The ultimate weights are determined from the balanced geometric mean equations as the following (Equation 22) [15].

$$
\text { 22. } \mathrm{a}_{\mathrm{m}}=\prod_{k=1}^{r}\left(\mathrm{a}_{\mathrm{mk}}\right)^{\mathrm{W}^{\prime}}
$$

In this stage (ranking the choices), using the AHP and the product of multiplication of indices weight matrices and the weight of the choices relative to the indices, the choices ranking is fulfilled.

Estimating the welfare equipment for the individuals affected by natural disasters

The sanitary condition of the affected people is overtly influenced by water, food, health, cleanliness, clothing, shelter, and healthcare. It is clear that the health of the affected people is not a separate issue, or it is not fulfilled by only providing health services, but it contains different components that are related to the lifestyle of the individuals. Hence, the set of needs related to health is of great significance in supplying the health of the individuals affected by natural disasters [16].

In this hierarchy, the healthcare needs for the affected people and supplying healthy and sufficient water and food are significant. The best way to supply the health of the affected people by the natural disasters is to provide proper and sufficient shelter, water, sewage, food, and first aid needs [17]. The result section discusses the required equipment needed by the studied village, considering the current instructions.

\section{Results}

Considering the region's faults (Figure 1) and using HAZUS instructions, the earthquake damage rate in the rural buildings, which are generally masonry and old, was determined. In this way, the intersection of the building capacity and seismic demand spectrum was prepared for the village buildings (Figure 5, e.g. Tikan Village). Subsequently, using the Spectral Displacement (SD) derived from this curve, the structure damage probability was calculated at different levels. Figure 6 presents the earthquake damage rate at the moderate level as an example. It has to be mentioned that due to the area of the region and the scattered villages, the right part shows the $450 \%$ zoom for higher clarity.

This study is developmental research based on purpose, and it is descriptive research based on nature and method. In the theoretical part of the study, using the library 


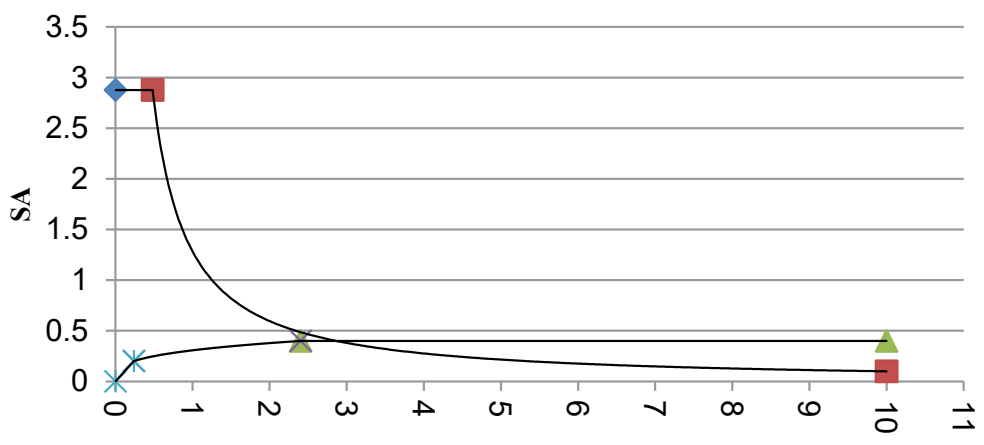

SD

IHlealth in

Emergencies and |D]isasters [Oluarterly

Figure 5. The intersection of masonry structure capacity urmm (low code) curve and seismic demand spectrum curve in Tikan Villag

method and studying the international and domestic studies and also referring to the experts in this field in the form of questionnaires and interview, the data related to the locating concepts and models, indices, and criteria were collected. In the practical part of this study, a part of the data were collected from the maps and data layers of ArcGIS in Golpayegan County, and a part collected from interviewing the experts of Management Crisis Organization of the Red Crescent. To analyze the collected layers, we used ArcGIS software. Among all the locating models, the two-dimensional logic model was selected to perform locating. Subsequently, fuzzy AHP was used for prioritizing and optimizing the indices in two stages. MATLAB was used for AHP and studying the compatibility of the experts' judgments and opinions, and also optimizing the weights criteria. Based on the previous earthquakes experience, the inhabitants tend to accommodate near their residences and their properties. Considering the great extent of the studied area, Vaneshan Village was selected as the pilot. The calculation related to the selection of the emergency settlement in the region is presented in the following.

To determine the indices' importance coefficients, they have to be compared with each other in pairs. The basis for the judgment in this comparison is a 9-quantity table. Based on the table and the study objectives, the strength of the $\mathrm{i}$ index was compared to the $\mathrm{j}$ index. Accordingly, for $\mathrm{n}$ indices, $\mathrm{n}^{\mathrm{n}}$ comparisons were carried out. In other words, in this study, considering the determined 11 major criteria and the 32 questionnaires, $11^{11} \times 32=9.12997346 \times 10^{12}$ comparisons were made to determine the strength of the major criteria. The results are presented in Tables 2, $3 \& 4$.

To calculate and evaluate the compatibility of the judgments, we used MATLAB. This analysis was carried out both by the formation of desired matrices and using the related formulas. Studying the compatibility of the judgments in the matrices of paired comparison of the criteria suggests that compatibility was not observed in

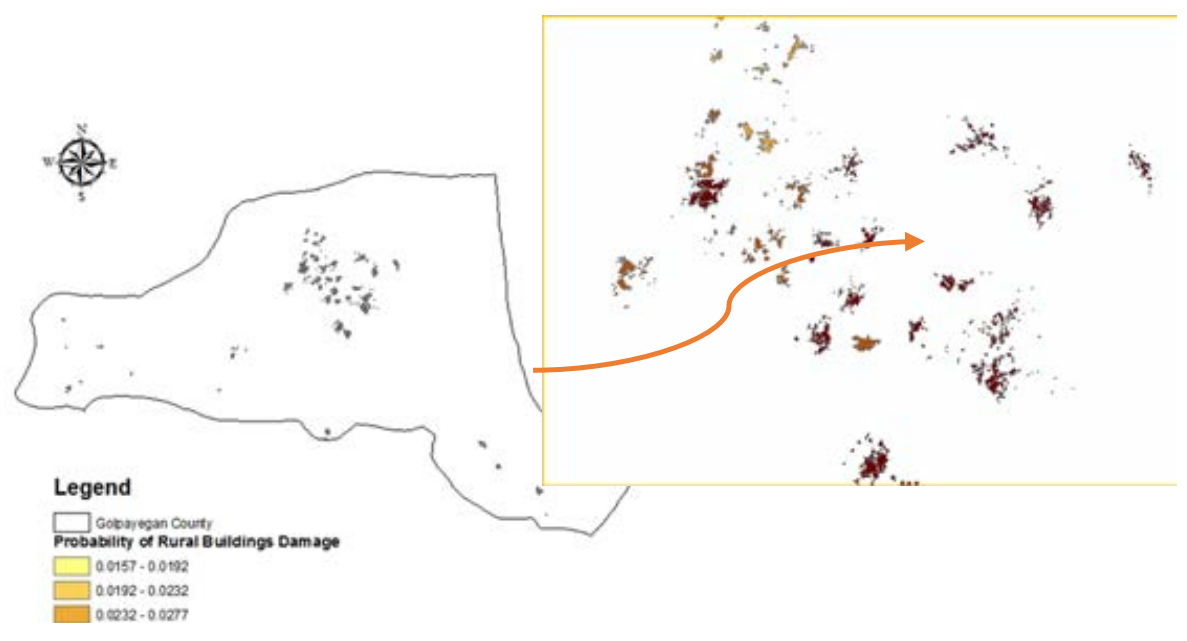

Figure 6. Probability of Rural Buildings Damage due to the Earthquake (moderate Level) 
Table 2. Fuzzy compound expansion matrix of locating indices

\begin{tabular}{|c|c|c|c|c|c|c|}
\hline \multirow{2}{*}{$\begin{array}{c}\text { Criterion } \\
\text { Proximity to the road network }\end{array}$} & \multicolumn{3}{|c|}{ Fuzzy Sum of Each Row } & \multicolumn{3}{|c|}{ Fuzzy Compound Expansion } \\
\hline & 13.96 & 19.48 & 25.55 & 0.0462 & 0.079 & 0.132 \\
\hline Access to water resources & 26.64 & 33.95 & 41.83 & 0.0882 & 0.13 & 0.217 \\
\hline Distance from fault & 35.211 & 44 & 52.67 & 0.1165 & 0.179 & 0.273 \\
\hline Distance from the river & 34.64 & 43.32 & 51.86 & 0.1147 & 0.0176 & 0.269 \\
\hline Proximity to health centers & 9.71 & 12.33 & 15.47 & 0.0321 & 0.0502 & 0.08 \\
\hline Proximity to the police station and security centers & 9.14 & 11.73 & 14.9 & 0.0303 & 0.0478 & 0.077 \\
\hline Distance from damaged areas and proximity to less damaged areas & 27.98 & 35.44 & 43.39 & 0.0926 & 0.1443 & 0.225 \\
\hline Distance from high voltage power lines & 18.71 & 25.28 & 32.6 & 0.0619 & 0.1 & 0.169 \\
\hline Soil type & 4.2 & 4.43 & 4.8 & 0.0139 & 0.018 & 0.024 \\
\hline Site slope & 9.11 & 11.87 & 14.93 & 0.0302 & 0.048 & 0.077 \\
\hline Site permeability & 3.4 & 3.68 & 4.14 & 0.0113 & 0.015 & 0.0215 \\
\hline
\end{tabular}

the judgments, for as it could be observed in Table 5, Consistency Ratio $(\mathrm{CR})=0.08725<0.1$.

In this study, a Boolean two-dimensional logic model was used for locating. The reason for selecting this method is its valuing system since the settlement centers nature is so that due to the sensitivity of their functions, the location for constructing settlement centers is either suitable or unsuitable. In this model, the locations that are not suitable based on the criteria are zero in this value system, and suitable locations are one in this value system.

First Stage: Determining the unsuitable locations using the preventive and limiting factors used for imple-

Table 3. Paired comparison matrix of major indices

\begin{tabular}{|c|c|c|c|c|c|c|c|c|c|c|}
\hline \multirow{2}{*}{$\begin{array}{c}\text { Criteria } \\
\text { Proximity to the road network }\end{array}$} & \multicolumn{10}{|c|}{ Preference Grade Si on Sk } \\
\hline & 0.43 & 0.138 & 0.156 & 1 & 1 & 0.381 & 0.452 & 1 & 1 & 1 \\
\hline Access to water resources & 1 & 0.711 & 0.729 & 1 & 1 & 0.953 & 1 & 1 & 1 & 1 \\
\hline Distance from the fault & 1 & 1 & 1 & 1 & 1 & 1 & 1 & 11 & 1 & 1 \\
\hline Distance from the river & 1 & 1 & 0.982 & 1 & 1 & 1 & 1 & 1 & 1 & 1 \\
\hline Proximity to health centers & 0.539 & 0 & 0 & 0 & 1 & 0 & 0.138 & 1 & 1 & 1 \\
\hline $\begin{array}{l}\text { Proximity to the police station and } \\
\text { security centers }\end{array}$ & 0.496 & 0 & 0 & 0 & 0.948 & 0 & 0.116 & 1 & 0.957 & 1 \\
\hline $\begin{array}{l}\text { Distance from damaged areas and } \\
\text { proximity to less damaged areas }\end{array}$ & 1 & 1 & 0.757 & 0.755 & 1 & 1 & 1 & 1 & 1 & 1 \\
\hline Distance from high voltage power lines & 1 & 0.696 & 0.408 & 0.426 & 1 & 1 & 0.363 & 1 & 1 & 1 \\
\hline Soil type & 0 & 0 & 0 & 0 & 0 & 0 & 0 & 0 & 0 & 1 \\
\hline Site slope & 0.502 & 0 & 0 & 0 & 0.961 & 1 & 0 & 0.222 & 1 & 1 \\
\hline Site permeability & 0 & 0 & 0 & 0 & 0 & 0 & 0 & 0 & 0.714 & 0 \\
\hline
\end{tabular}


Table 4. Calculation of weights indices in locating emergency settlement in rural regions

\begin{tabular}{cccc}
\hline Criterion & Preference grade & Normalization of preference grade & Weight criteria \\
\hline Proximity to the road network & 0.138 & 0.35 & 0.35 \\
\hline Access to water resources & 0.711 & 0.179 & 0.18 \\
\hline Distance from Fault & 1 & 0.253 & 0.253 \\
\hline Distance from the river & 0 & 0.248 & 0.249 \\
\hline $\begin{array}{c}\text { Proximity to health centers } \\
\text { Proximity to the police station and security } \\
\text { centers }\end{array}$ & 0 & 0 & 0 \\
\hline $\begin{array}{c}\text { Distance from damaged areas and proximity to } \\
\text { less damaged areas }\end{array}$ & 0.757 & 0 & 0.192 \\
\hline $\begin{array}{c}\text { Distance from high voltage power lines } \\
\text { Soil type }\end{array}$ & 0 & 0.191 & 0.092 \\
\hline Site slope & 0 & 0.92 & 0 \\
\hline Site permeability & 0 & 0 & 0 \\
\hline
\end{tabular}

menting this stage of the model. The results are presented in Figure 7.

Second Stage: Determining the suitable locations using the facilities of the region. To implement this stage, the current standards were used. The results are presented in Figure 8.

Third Stage: Determining the most suitable centers by considering the facilities and limitations of the region. The combination of the facilities and limitations layers and selecting the choices using the software are presented in Figure 9.

\section{Determining the final score (priority) of the choices}

In this stage, by combining the scores of the criteria and the choices derived from the paired comparison matrices, the final score of each choice was determined. To reach this, we used Sa'ati's principle of hierarchical composi- tion, and by considering all the judgments in all stages of hierarchy, the "priority vector" was derived. The ultimate weight of each choice is derived from the multiplication of the criteria in the choices' weights. Considering the calculations, the final score of settlement choices are as the following:

$$
\begin{array}{lll}
\mathrm{W}_{1}=0.217042 & \mathrm{~W}_{2}=0.187264 & \mathrm{~W}_{3}=0.133144 \\
\mathrm{~W}_{4}=0.151035 & \mathrm{~W}_{5}=0.158108 & \mathrm{~W}_{6}=0.15136
\end{array}
$$

Hierarchical structure of locating temporary settlement centers was presented in Figure 10. Considering the results in Figure 11, we could observe that the best choice is choice number one, and after that, choice number two, choice number five, choice number six, choice number four, and choice number three. The results are seen in Figure 12.

The required logistic items, including resettlement, food, water, search, rescue and relief operations, and

Table 5. Studying the compatibility of the judgments in determining the major indices importance coefficients using MATLAB

\begin{tabular}{cccc}
\hline \multicolumn{2}{c}{ Incompatibility Rate } & & \\
\hline $\mathrm{CRm}$ & $\mathrm{CRq}$ & Compatible Status \\
0.0349 & 0.0875 & \\
\hline titeatth in \\
Emergencies and [D]isasters [Oluarterly
\end{tabular}

The Am matrix consists of intermediate values of expert preferences; the Ag matrix consists of the upper and lower boundary averages. 


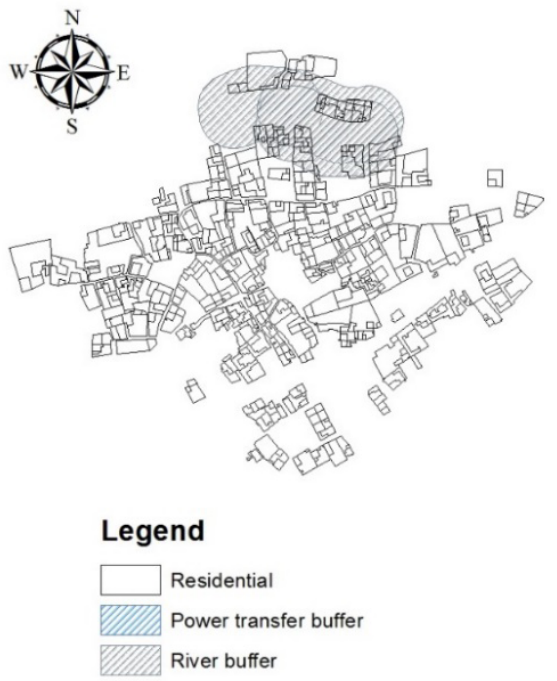

Figure 7. Areas and their ranges that are unsuitable for settlement

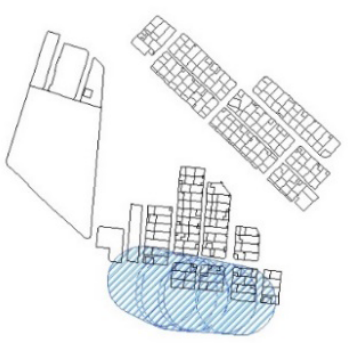

IHealth in

Emergencies and |D]isasters [O]uarterly healthcare, were determined by considering the studied region's population and current standards (in cases based on age and gender). The results of the calculations are presented in Table 6.

\section{Discussion}

In general, spatial maps, the degree of vulnerability of structures and population, and reports provide the user with the degree of damage to structures in each village. Also, managers can fully direct and manage rescue, search and rescue operations and prevent wasting golden rescue time. Besides, the existence of such scenarios and plans before the hazard is a scientific guide. It helps to determine the strengths and weaknesses of the village against earthquakes for managers and determine a procedure to fix the weaknesses and increase the safety factor of the village.

According to the research questions and information collected from the geographical layers and the limitations of these layers, the criteria for distance from faults and mountain falls, distance from rivers and canals, distance from damaged areas, proximity to water, and

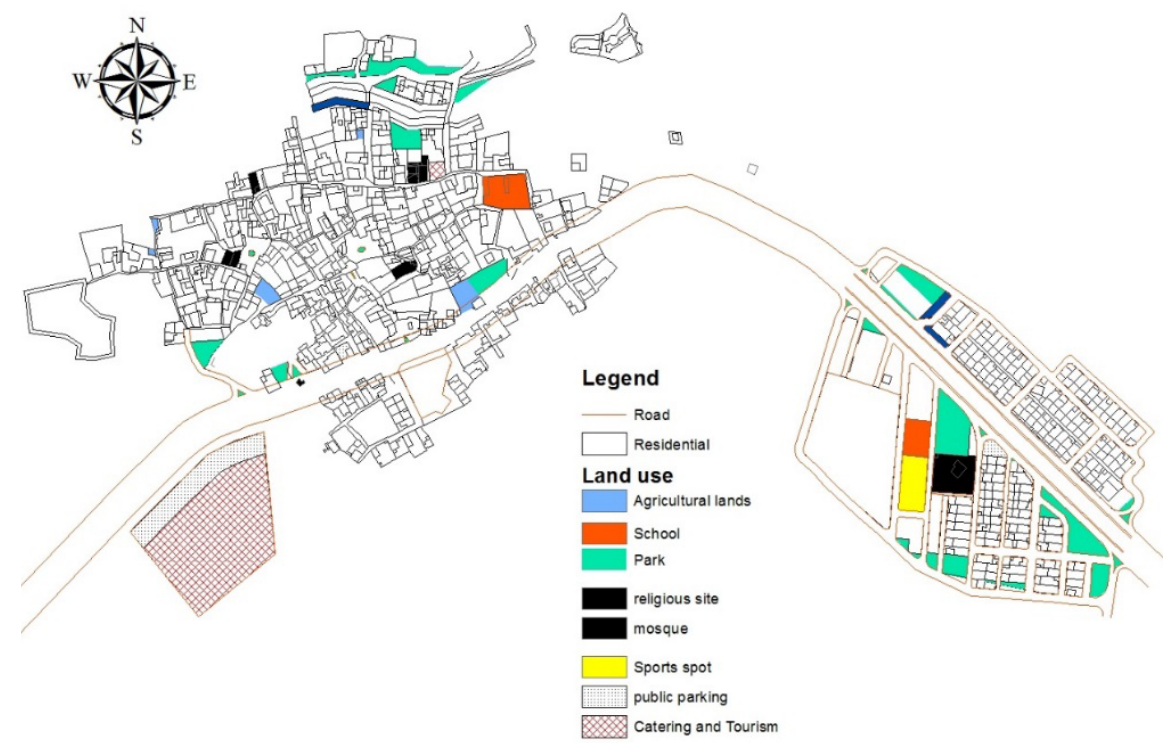

Figure 8. Layers with the value of one for the temporary settlement in the region 


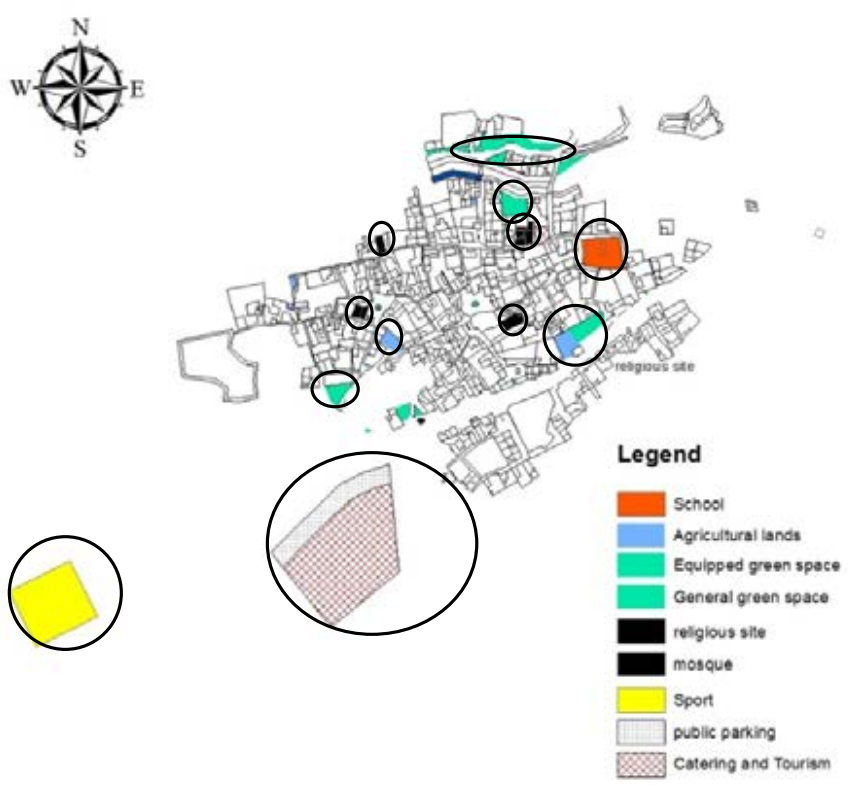

Figure 9. Map of suitable locations for settlement in the region

proximity to access roads are the most important criteria and factors in the study area. In this research, GIS has been used as a system for applying location indicators and location analysis. There are different models for locating with GIS. The use of these models depends on the type of location desired by the researcher. Therefore, in this research, the Boolean model has been used due to its evaluation system, which is a suitable model for locating emergency accommodation and relief centers and other cases that have a particular sensitivity.

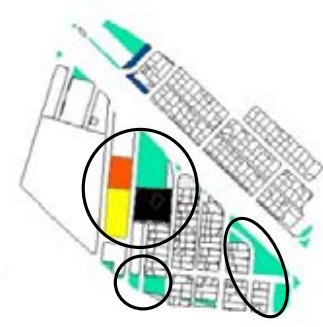

Hlealth in
Emergencies and |D]isasters [Oluarterly
Regarding the study area, the results of the damage analysis of the area show that the rate of damage with extensive and complete levels in the villages is very high, which leads to a large number of homeless people with the urgent need to provide adequate shelter. This endower requires a lot of money, and the relevant managers should already be thinking about finding financial resources for it. This issue is not only related to the study area and applies to the whole of Iran.

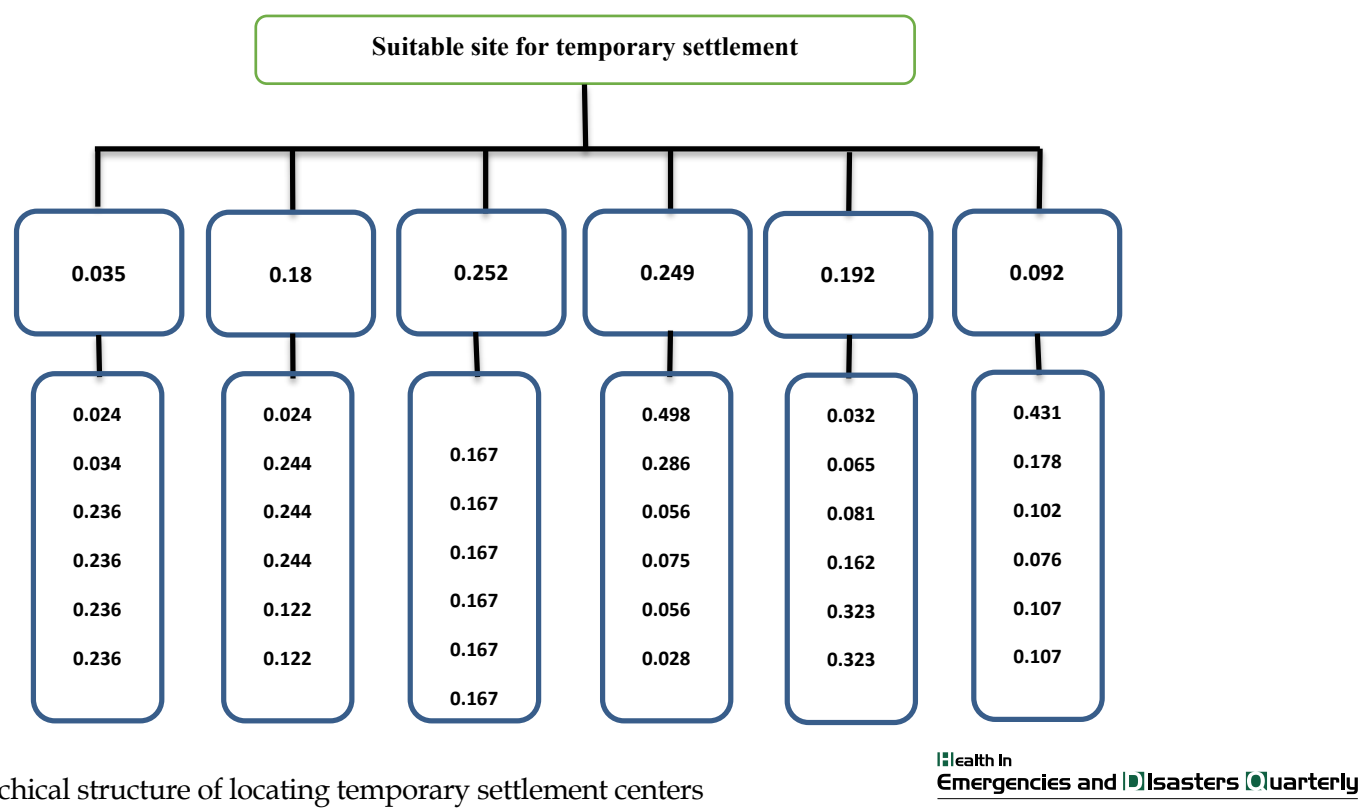

Figure 10. Hierarchical structure of locating temporary settlement centers 


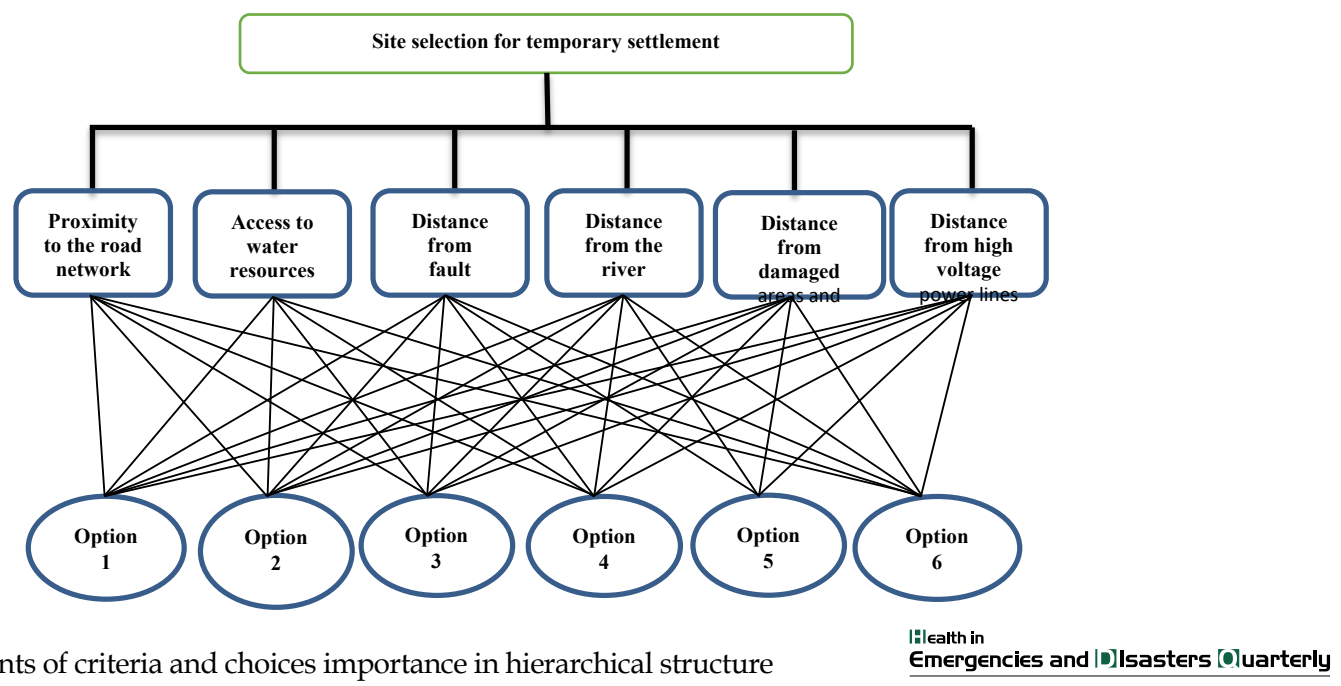

Figure 11. Coefficients of criteria and choices importance in hierarchical structure

The earthquake risk analysis method used in this study is a suitable approach for assessing and analyzing asset risk. This risk analysis can be a beneficial and reliable source for making decisions in various fields such as resilience, emergency response, and detailed design. For example, by identifying high-risk areas, assets (residential areas) can be prioritized for retrofitting. It is also possible to use the results related to high-risk areas due to earthquake risk in emergency response and emergency decision-making decisions. On the other hand, the first and most necessary prerequisite for locating temporary housing is the existence of damage analysis results in the area. In this study, the risk of earthquake damage was widely determined according to the faults in the area.
It is very difficult and unexpected to consider all aspects related to a subject in scientific research. To carry out the various stages of this research, a wide range of issues related to this topic appeared in front of researchers, which may not be without merit for those interested in this field. Some of these suggestions for future research include:

- Examine other aspects of risk, such as economic and social aspects.

- Determining the components for which the risk of rural areas increases.

- Consider other hazards in the area, including fire, liquefaction, and landslides.

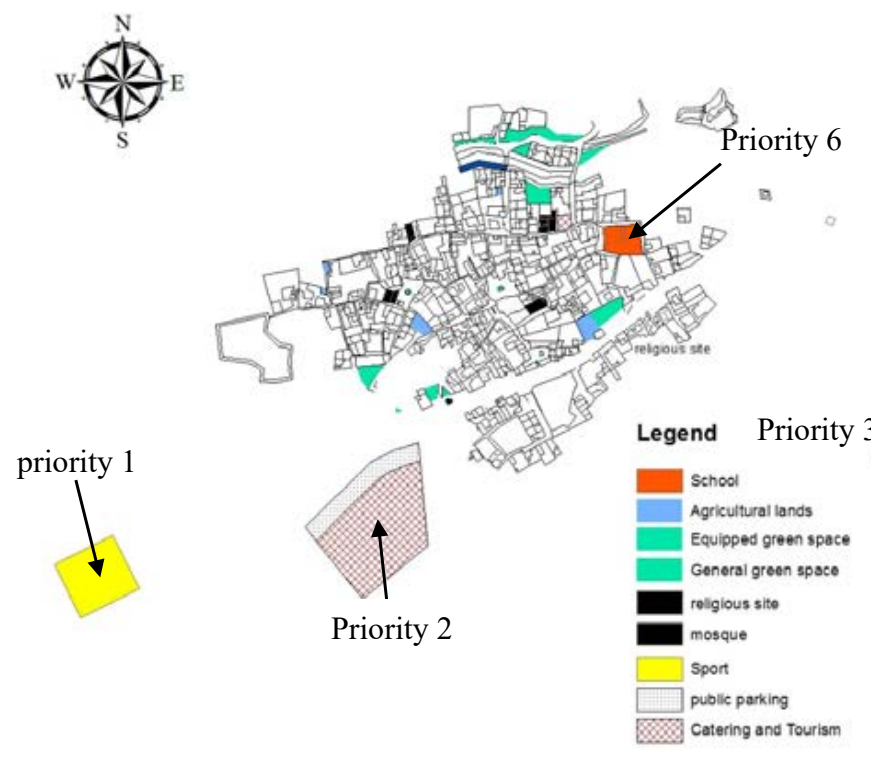

Figure 12. The ultimate map of the settlement priorities in the studied region 
Table 6. The required logistic items in the studied region

\begin{tabular}{|c|c|c|c|}
\hline Services Categories & Required Items Considering the Categorization & Required Amount & Source \\
\hline \multirow{5}{*}{ Settlement Initial Needs } & The number of the population needing resettlement & 2024 & \multirow{5}{*}[18]{} \\
\hline & Number of families needing resettlement & 204 & \\
\hline & Tent & 204 & \\
\hline & Carpet & 408 & \\
\hline & Blanket & 6072 & \\
\hline \multirow{5}{*}{ Food } & Wheat flour, Edible corn, Wheat bran, Corn ears or Rice (Grains) & 174.064 & \multirow{5}{*}[19]{} \\
\hline & Dried beans or lentils (Legumes/Grains) & 20.24 & \\
\hline & & & \\
\hline & Edible Oil & 10.12 & \\
\hline & Salt & 2.024 & \\
\hline \multirow{5}{*}{ Water Supply Method } & Number of water taps (extraction water $7.5 \mathrm{~L} / \mathrm{min}$ ) & 9 & \multirow{12}{*}[19]{} \\
\hline & Number of water pumps & 5 & \\
\hline & Number of wells & & \\
\hline & Number of wells & 6 & \\
\hline & Number of water supplies & 22 & \\
\hline \multirow{7}{*}{ Number of hygiene items } & Number of toilets (better to be latrines) & 102 & \\
\hline & 100-L trash can & 21 & \\
\hline & Number of baths & 41 & \\
\hline & & & \\
\hline & Bathing Soap $250 \mathrm{~g}$ & 2024 per month & \\
\hline & Soap $200 \mathrm{~g}$ & 2024 per month & \\
\hline & Suitable menstrual health items, such as washable cotton fabrics & 1012 & \\
\hline \multirow{2}{*}{$\begin{array}{l}\text { Number of search and sur- } \\
\text { vival dogs }\end{array}$} & Search dogs & 1 & \multirow{12}{*}[18]{} \\
\hline & Live locator & 1 & \\
\hline \multirow{4}{*}{$\begin{array}{l}\text { Estimation of the number of } \\
\text { families needing search and } \\
\text { rescue operations and relief } \\
\text { services }\end{array}$} & Number of families needing search and rescue operations & 21 & \\
\hline & Number of families needing relief services & 204 & \\
\hline & Number of operation teams & 3 & \\
\hline & Number of settlement teams and food & 2 & \\
\hline \multirow{6}{*}{$\begin{array}{l}\text { Specialized tools required for } \\
\text { search and rescue operations }\end{array}$} & $\begin{array}{l}\text { Number of families needing search and rescue operations and } \\
\text { relief services }\end{array}$ & 21 & \\
\hline & Rescue vehicle & 1 & \\
\hline & Ambulance & 2 & \\
\hline & Motorcycle & $*$ & \\
\hline & Helicopter & $*$ & \\
\hline & Communication vehicle & $*$ & \\
\hline
\end{tabular}


- Assessing the impact of risk management measures based on risk maps of the region.

- Combining fuzzy systems with genetic algorithms to achieve more optimal solutions.

- Using artificial neural networks in locating temporary accommodation.

\section{Ethical Considerations}

\section{Compliance with ethical guidelines}

There were no ethical considerations to be considered in this research.

\section{Funding}

This research did not receive any grant from funding agencies in the public, commercial, or non-profit sectors.

\section{Authors' contributions}

Both authors equally contributed to preparing this article.

\section{Conflict of interest}

The authors declared no conflict of interest

\section{References}

[1] Munich Re. Munich Re's analysis of natural catastrophes in 2002 [Internet]. 2002 [Updated 2002 December 30]. Available from: https://reliefweb.int/report/world/munich-res-analysis-natural-catastrophes-2002

[2] Sigma RS. Preliminary Swiss Re sigma estimates of catastrophe losses in 2005, high casualty count and record insured losses of USD 80 billion. 2005. https://www.swissre.com/ media/news-archive/archive-2005.html

[3] Ganjehi S, Omidvar B, Norouzi Khatiri KH, Malekmohammadi B. [Analysis of safety parameters in the selection of optimal routes for search and Rescue (Case study: 13 Aban neighborhood of Tehran) (Persian)]. Quarterly Scientific Journal of Rescue and Relief. 2014; 6(1). http://jorar.ir/article-1-179-fa.html

[4] Norouzi Khatiri K, Omidvar B, Malekmohammadi B, Ganjehi S. [Multi-hazards risk analysis of damage in urban residential areas (case study: Earthquakeandflood hazards in Tehran-Iran) (Persian)]. Journal of Geography and Environmental Hazards. 2013; 2(7):53-68. [DOI:10.22067/geo.v0i0.20948]

[5] Macabuag J, Guragain R, Bhattacharya S. Seismic retrofitting of non-engineered masonry in rural Nepal. Proceedings of the Institution of Civil Engineers-Structures and Buildings. 2012; 165(6):273-86. [DOI:10.1680/stbu.10.00015]
[6] Wu Q, Ye S, Wu X, Chen P. Risk assessment of earth fractures by constructing an intrinsic vulnerability map, a specific vulnerability map, and a hazard map, using Yuci City, Shanxi, China as an example. Environmental Geology. 2004; 46(1):104-12. [DOI:10.1007/s00254-004-1020-5].

[7] Tudes S, Yigiter ND. Preparation of land use planning model using GIS based on AHP: Case study Adana-Turkey. Bulletin of Engineering Geology and the Environment. 2010; 69(2):235-45. [DOI:10.1007/s10064-009-0247-5]

[8] Donevska KR, Gorsevski PV, Jovanovski M, Peševski I. Regional non-hazardous landfill site selection by integrating fuzzy logic, AHP and geographic information systems. Environmental Earth Sciences. 2012; 67(1):121-31. [DOI:10.1007/ s12665-011-1485-y]

[9] Liu J, Fan Y, Shi P. Response to a high-altitude earthquake: The Yushu Earthquake example. International Journal of Disaster Risk Science. 2011; 2(1):43-53. [DOI:10.1007/s13753-011-0005-8]

[10] Kaptan K. Seismic risk assessment for rural areas. Küresel Mühendislik Çalışmaları Dergisi. 2015; 2(1):44-50. https:// dergipark.org.tr/en/pub/kmcd/issue/19277/204754

[11] Zare M. Contribution a letude des mouvements forts en Iran: Du catalogue aux lois d'att'enuation [PhD. dissertation]. France: Universit'e Joseph-Fourier; 1999. https:/ / tel.archivesouvertes.fr/tel-00708207

[12] Federal Emergency Management Agency. Hazus® Estimated Annualized Earthquake Losses for the United States [Internet]. 2017 [Updated 2017 April]. Availeble from: https://www.fema.gov/sites/default/ files/2020-07/fema earthquakes_hazus-estimated-annualized-earthquake-lossesfor-the-united-states_20170401.pdf

[13] Azar A, Faraji H. [Fuzzy management science (Persian)] Tehran: Agahe; 2010. https://www.agah_3463

[14] Asqarpur MJ. [Multi-criteria decisions (Persian)]. Tehran: University of Tehran Book Publishing Company; 2008. https://press.ut.ac.ir/book_2372.html

[15] Mo'meni M. [New research topics in operations (Persian)] Tehran: Agah; 2006. https://www.agahbookshop.com_8690

[16] Jahangiri K. [Principles of crisis management (Persian)] $1^{\text {th }}$ ed. Tehran: Institute of Applied Science \& Technology, Red Crescent Society; 2007. https://www.gisoom.com/ book/11017633

[17] Fayyazi M, Azizkhani N. [Crisis nutrition management: For use in nutrition management and food aid in crises (Persian)]. Tehran: Institute of Applied Science \&Technology, Red Crescent Society; 2009. http://centlib.iums.ac.ir:8800/site/ catalogue/ 83282

[18] Iranian Red Crescent Society. [Review the instructions for awarding and upgrading the title of the instructions for rescuers and rescuers (Persian)] [Internet]. 2016 [Updated 2016]. Available from: http:/ / raro.ir/images/PDF/Dastor/Daraje.pdf

[19] Sphere Project Staff. Sphere project: Humanitarian charter and minimum standard in disaster response. United Kingdom: Practical Action Publishing; 2011 [DOI:10.3362/9781908176202] 
This Page Intentionally Left Blank 